\title{
Bronchocentric granulomatosis associated with seropositive polyarthritis
}

\author{
HH BERENDSEN, N HOFSTEE, PD KAPSENBERG, DR SIEWERTSZ VAN REESEMA, \\ JJ KLEIN
}

From the Departments of Pulmonology and Rheumatology, St Jozef Hospital, and Laboratory of Pathology
and Microbiology, Deventer, The Netherlands

Bronchocentric granulomatosis was first described by Liebow' ${ }^{\prime}$ and is a form of pulmonary granulomatosis and angiitis. The disease is characterised by its clinical and morphological features but the clinical ${ }^{2}$ and radiographic ${ }^{3}$ manifestations are rather non-specific. Lung biopsy is necessary to establish the diagnosis and granulomatous inflammation, centred predominantly on the bronchi and bronchioles, is pathognomonic. According to the original description of Liebow, ${ }^{1}$ one of the characteristics of bronchocentric granulomatosis is the absence of extrapulmonary lesions. We here report a case of bronchocentric granulomatosis associated with seropositive polyarthritis.

\section{Case report}

In August 1981 a 58 year old man was admitted to another hospital with fever and an abnormal chest radiograph. He was treated initially with penicillin for suspected bacterial pneumonia; later doxycycline and erythromycin were given without definite improvement. When tomography subsequently showed enlarged hilar glands with persistent pulmonary shadowing, sarcoidosis was suspected. No biopsy was performed and prednisolone ( $20 \mathrm{mg}$ daily) was started. After initial improvement, the clinical and radiographic manifestations worsened. In November 1981 he was referred to our hospital for further investigation. He was reported to have had mild asthmatic symptoms 20 years earlier, a myocardial infarction in 1975, and surgery for diverticulitis of the colon in early 1981 .

Shortly before transfer the patient developed polyarthritis. On admission he appeared ill, with a temperature of $39^{\circ} \mathrm{C}$, a persistent cough, haemoptysis, dyspnoea at rest, and chest pain. He had no history of Raynaud's phenomenon. On physical examination breath sounds were diminished over the lower part of the right lung and no wheezes were heard. The metacarpophalangeal and proximal interphalangeal joints were swollen and painful but there were no subcutaneous nodules. The chest radiograph (fig 1) showed bilateral macronodular lesions; the right lung, which showed cavitation, was more affected than the left.

The haemoglobin concentration was $6 \mathrm{~g} / \mathrm{dl}$; the packed cell volume was $31 \%$ and the white cell count $15.1 \times 10^{9} / 1$ with a normal differential count. The erythrocyte sedimen-

Address for reprint requests: Dr HH Berendsen, Department of Pulmonary Diseases, University Hospital, 59 Oostersingel, 9700 RB Groningen, The Netherlands.

Accepted 9 November 1984 tation rate (ESR) was $145 \mathrm{~mm}$ in one hour. Electrolytes and renal and hepatic function were normal. The results of tests for rheumatoid factor were positive (Rose Waaler $1 / 512$, latex fixation $1 / 320$ ) and antinuclear factor was present in a titre $\geqslant 1 / 10$; double stranded DNA antibodies and lupus erythematosus cells were not detected. Precipitins against Aspergillus fumigatus and Candida albicans could not be demonstrated. A tuberculin skin test gave a negative result. There were no abnormalities in the upper respiratory tract and a biopsy from the nasal mucosa showed nothing abnormal. On rigid bronchoscopy a small quantity of blood was visible in the orifice of the apical segment of the right lower lobe. Culture of bronchial washings from this segment yielded Escherichia coli and an anaerobic streptococcus. To establish a definitive diagnosis an open lung biopsy from the right lower lobe was performed. No synovial biopsy specimens were taken. Histological examination (fig 2) showed necrotising granulomatous inflammation centred predominantly on and destroying bronchioles. The adjacent pulmonary arteries showed vasculitis without evidence of bacteria or fungi. These features were consistent with bronchocentric granulomatosis. The dose of prednisolone was increased to $100 \mathrm{mg}$ daily and the patient responded well. Aftor the dose had been tapered to $20 \mathrm{mg}$ daily over an eight week period, the polyarthritis again worsened and the dose was increased temporarily to $30 \mathrm{mg}$.

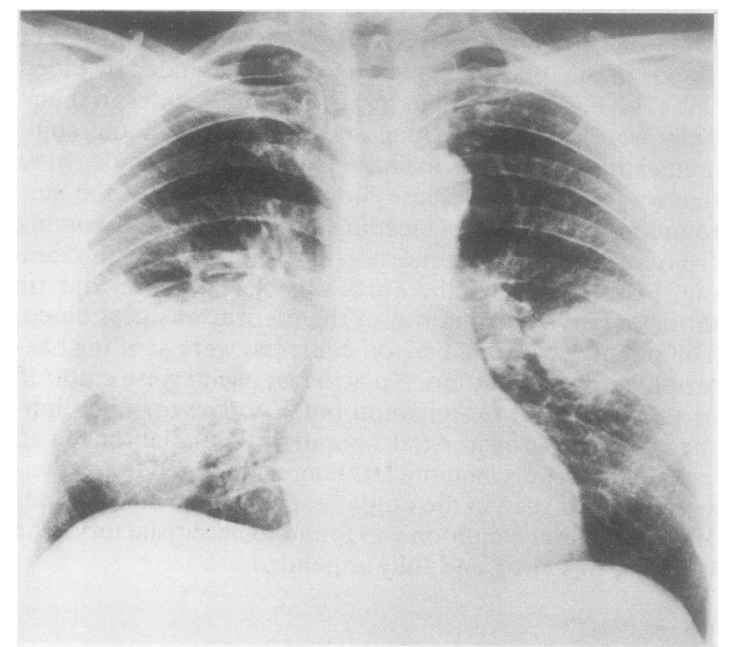

Fig 1 Chest radiograph on admission in November 1981. 


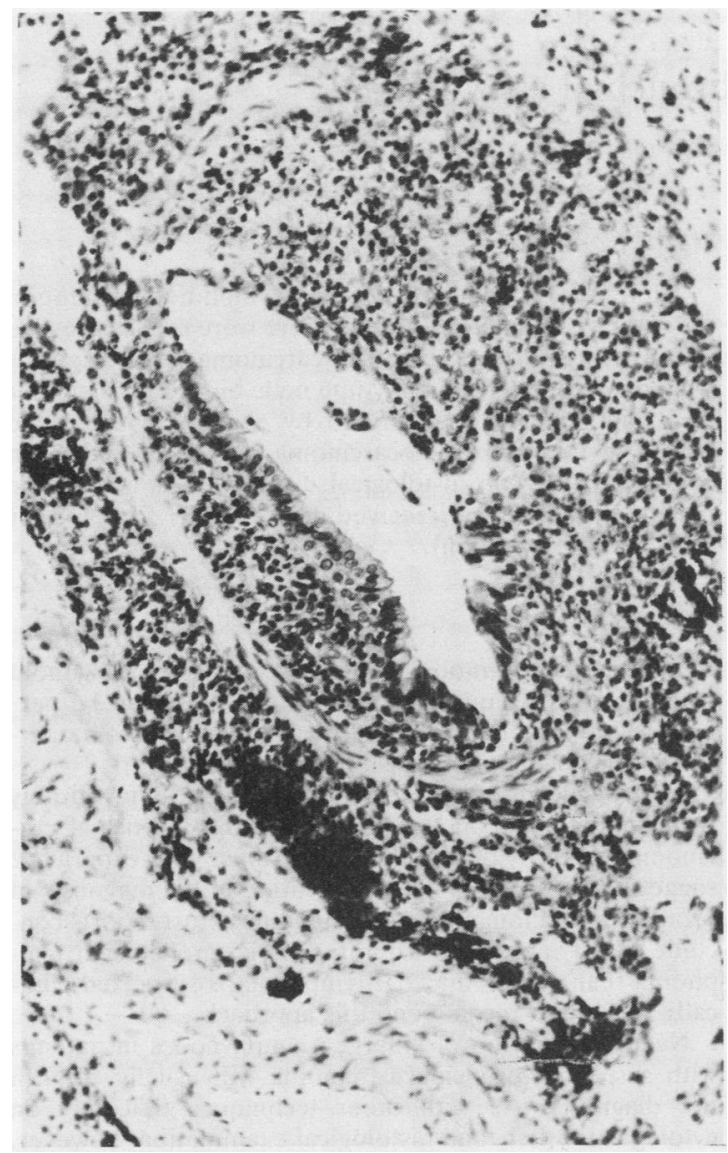

Fig 2 Section of lung biopsy specimen showing peribronchial granulomatous infiltrate with destruction of the bronchiolar wall. Remnants of ciliated epithelium can be seen on one side and an adjacent vessel shows minimal changes. Anthracotic pigment is present between the bronchiole and the vessel. (Haematoxylin and eosin, $\times 95$.)

Six months after thoracotomy the chest radiograph had cleared completely and by November 1983 prednisolone could be stopped. The patient subsequently had no pulmonary symptoms and the radiograph has remained normal. His persisting mild joint symptoms have not required additional treatment. The ESR remains mildly raised at $32 \mathrm{~mm}$ in one hour.

\section{Discussion}

The natural history of bronchocentric granulomatosis varies: spontaneous regression of lesions has been described ${ }^{4} \mathrm{~s}$ and resection of a solitary lesion can apparently be curative.$^{4-6}$ In the series of Koss $\mathrm{et}^{\mathrm{al}} \mathrm{l}^{5}$ all the patients survived during a follow up period ranging from two months to 14 years, while Saldana ${ }^{6}$ described two deaths in a series of 17 patients. The pulmonary fesions of bronchocentric granulomatosis usually respond well to steroid treatment but the dose and duration of treatment has to be titrated against the clinical and radiographic response. Prolonged treatment may be necessary. Hellems et al ${ }^{7}$ described a patient with bronchocentric granulomatosis and polyarthritis in whom treatment was started with $60 \mathrm{mg}$ prednisolone a day, and who after 4 years of treatment was still steroid dependent. Clee et al $l^{8}$ noted rapid improvement in a patient who started at $20 \mathrm{mg}$ daily but exacerbation occurred when he was weaned from the drug after two years; in the subsequent three years this patient remained well on $5 \mathrm{mg}$ prednisolone daily. Before the diagnosis was made our patient had deteriorated while having treatment with $20 \mathrm{mg}$ daily and there was rapid improvement after this had been increased to $100 \mathrm{mg}$ daily. Subsequently the steroids could be tapered, and after two years complete withdrawal of treatment was possible.

It has been noted by Katzenstein et al $^{4}$ and others ${ }^{8}$ that non-invasive aspergillus is often seen in biopsy specimens from patients with bronchocentric granulomatosis, especially in those with evidence of asthma, suggesting that fungi might play a part in the pathogenesis of the condition. In many other patients, however, including the one described here, no fungi were observed.

In his original description' Liebow noted the absence of extrapulmonary lesions in bronchocentric granulomatosis. In the present case, however, we observed a seropositive polyarthritis, and the patient reported by Hellems et al had a seronegative arthritis. Other extrapulmonary lesions have been described by others and Wiedemann $e t a l^{9}$ reported eye lesions. In neither of these cases were fungi seen in biopsy material. The pathogenesis of bronchocentric granulomatosis remains uncertain but extrapulmonary associations are inceasingly recognised and fungal colonisation of the bronchial tree does not appear to be essential for development of the condition.

We gratefully acknowledge the help of Professor JD Elema, Groningen, The Netherlands, and Professor ALA Katzenstein, Birmingham, Alabama, USA, who reviewed the biopsy, and Dr A Löwenberg for reading the manuscript.

\section{References}

1 Liebow AA. The J Burns Amberson Lecture. Pulmonary angiitis and granulomatosis. Am Rev Respir Dis 1973;108:1-18.

2 Edwards $\mathrm{CW}$. Vasculitis and granulomatosis of the respiratory tract. Thorax 1982;37:81-7.

3 Robinson RC, Wehunt WD, Tsou E, Koss MN, Hochholzer L. Bronchocentric granulomatosis: roentgenographic manifestations. Am Rev Respir Dis 1982;125:751-6.

4 Katzenstein AL, Liebow AA, Friedman PJ. Bronchocentric granulomatosis, mucoid impaction and hypersensitivity reactions to fungi. Am Rev Respir Dis 1975; 111:497-537.

5 Koss MN, Robinson RG, Hochholzer L. Bronchocentric granulomatosis. Hum Pathol 1981;12:632-8.

6 Saldana MJ. Bronchocentric granulomatosis; clinicopathologic observations in 17 patients. Lab Invest 1979;40:281-2.

7 Hellems SO, Kanner RE, Renzetti AD. Bronchocentric granulomatosis associated with rheumatoid arthritis. Chest 1983;5:831-2.

8 Clee MD, Lamb D, Urbaniak SJ, Clark RA. Progressive bronchocentric granulomatosis: case report. Thorax 1982;37:947-9.

9 Wiedemann HP, Bensinger RE, Hudson LD. Bronchocentric granulomatosis with eye involvement. Am Rev Respir Dis 1982;126:347-50. 